\title{
Factors Influencing Tax Income: A Panel Data Analysis
}

\author{
Prianto Budi Saptono*, Gustofan Mahmud ${ }^{* *}$ \\ * Faculty of Administrative Sciences, Universitas Indonesia \\ ** Pratama Kreston Tax Research Institute \\ DOI: 10.29322/IJSRP.11.08.2021.p11657 \\ http://dx.doi.org/10.29322/IJSRP.11.08.2021.p11657
}

\begin{abstract}
This study analyzes the factors that are thought to affect tax revenues. The data used in this study is panel data involving seven ASEAN countries for 2009 - 2015. The Hausman test was carried out to determine the estimation model correctly, and the results revealed that the fixed-effects model was preferred. Based on the fixed-effects model's estimation results, this study finds that per capita income, the industrial sector's contribution in GDP, and trade liberalization have a significant and positive effect on tax revenue. In contrast, inflation worsens the flow of tax revenues significantly. Based on the results of this study, we recommend several policies that can be taken to increase the productivity of tax revenues by focusing on those four macroeconomic factors.
\end{abstract}

Index Terms- Tax Revenue, Income Per Capita, Industrial Sectors, Inflation, and Trade Openness

\section{INTRODUCTION}

The government's role is needed because the market cannot solve their problems (III, 2005). The failure of the market in question is the market's inability to provide public goods, resolve the macroeconomic problems, and resolve the negative externalities of the private sectors. For public goods, there are no private sectors that are able and willing to provide it. On the other hand, the demand for public goods continues to rise. Meanwhile, the market mechanism cannot solve macro-economic problems like recession, inflation, unemployment, and income distribution. For externalities, every decision affects the private sector for social, economic, and political surroundings. Indeed, this is dangerous if the adverse effects arising from the private sector. Therefore, the role of government is needed to resolve the issue.

Government has three functions: allocation, distribution, and stabilization (Musgrave, 1939). Allocation function is indicated by a government policy that ensures the provision of goods and services in an area with sufficient quantities, either through the market or provided directly by the government. The distribution function is shown by an equitable distribution of national wealth that all segments can enjoy in society. The stabilization function is shown by the efforts to stabilize the prices that can be achieved through fiscal and monetary policy. Through monetary policy may be carried out by regulating the money supply and interest rates. Meanwhile, fiscal policy can be implemented by adjusting the government's revenues and expenditures.

According to Stiglitz (1991), there are two fundamental theorems of welfare economics. The first theorem is that welfare can be achieved by efficiently allocating resources in the market competitive. In addition, it is assumed that the information about the market perfectly and efficient allocation of resources (Pareto efficient). The second theorem is the answer if the first theorem is not reached. If efficiency is not achieved, then there is room for the government to intervene through the redistribution of wealth. Redistribution of wealth can be done through taxation and government spending, i.e., $W=f(T x, G)$. The second theorem shows that tax revenue is essential to fund governance activities, especially in distributing society's wealth. The role and function of government in an economy can be as good as the availability of adequate funds required. So, it has become a necessity for optimization of tax revenue to support the activities of governance. To optimize the tax revenue necessary to plan and prepare tax revenue models involving factors that can affect tax revenue.

Countries that are members of the Association of Southeast Asian Nations (ASEAN) are ideal countries to study what factors can determine the amount of government tax revenue flows for some reasons. First, the ability of the government to collect taxes in these countries is relatively low. It was reflected in the low tax ratio in these ASEAN countries. Based on data obtained from the World Bank, the tax ratio in ASEAN countries has always been below 20\% of GDP during 2009 - 2015, including for emerging market countries such as Indonesia, Malaysia, Thailand, and the Philippines, even for developed countries such as Singapore. The tax ratio below $20 \%$ of GDP is still too small for emerging market countries. Because ideally, for emerging markets, the tax ratio should reach $17-20 \%$ of GDP. The tax ratio in these countries is also lower than the average tax ratio in middle-income countries, reaching $17.8 \%$ of GDP. Second, Based on data obtained from the World Bank, the primary source of state revenue from the seven ASEAN countries is taxes. From 2010-2015, in general, tax revenues dominated other state revenues (non-tax revenues and grants), contributing more than $60 \%$ of total state revenues. It has proved that tax revenue plays a crucial role in funding government activities, especially in the economic sectors. For these reasons, we use the econometric panel technique on a sample of seven ASEAN countries during the 2009 -2015 period to study what factors can affect tax revenues in these countries. 
This paper is structured as follows. In section 2, we provide the results of previous research on the factors that influence tax revenue. Section 3 is devoted to research methodology. In Section 4, we describe the results of the study and the discussion thereof. Section 5 we conclude.

\section{LITERATURE REVIEW}

Numerous previous studies have scientifically proven the factors that can affect the flow of government tax revenue. (Gupta, 2007) showed that GDP per capita and trade openness could significantly affect tax revenue performance. According to Immervoll (2005), inflation is essential to stimulate an increase in the tax revenue experienced delays in collecting taxes. The idea was reinforced by (Prammer \& Reiss, 2015), who was stated that during tax and social security contributions imposed by proportional at current prices, the tax revenue would be in line with inflation. In addition, they also enhanced that the progressive tax can increase tax revenues more quickly when inflation occurs. It means that tax revenues increase due to inflation. However, if the tax is nominally taxed, inflation will harm tax revenue.

According to Ayenew (2016), the long-term real GDP per capita and industrial sectors positively affect tax revenue. While inflation negative and significant impact on tax revenue. In the short-term real per capita GDP has a negative and significant effect on tax revenue. At the same time, the industrial sector's contribution remained positive and significant impact on tax revenue.

According to Karagöz (2013), increasing per capita income will be impacted positively to tax revenue. When the per capita income increases, the "ability to pay" taxes may be increased. In addition, the amount of tax paid by the taxpayer and received by the government depending on the tax rate and income (Fenochietto \& Pessino, 2013). Revenue itself can be changed according to the change of real GDP. That is, real GDP reflects the income levels in a country. When the level of real GDP increases, income communities in a country increase. On the opposite, when the GDP falls, income within a country also decreased.

During the expansion, the real GDP of the country has increased. It indicates that corporate profits increase and community wages increase, which drives higher public consumption. Such situations correspond to an increase in taxable capacity. Likewise, when a country experiences a recession, then the real GDP of the country has decreased. This decline causes profit, and public wages also decrease so that private consumption will be hampered. Hence, the potential taxes that the government can collect are reduced.

As one of the sectors that dominate the contribution to the GDP in many countries, the industrial sectors are to be reckoned as one of the variables that influence the formation of GDP. Therefore, a positive relationship is expected between industrial and tax revenue (Gaalya, 2015). The increase in revenue in the industrial sectors will affect GDP, further increasing tax revenue. In addition, companies in the industrial sector usually have good financial reports that tax officials can audit. Hence, levying taxes on this sector is more likely than other sectors, such as agriculture (Eltony, 2002).

According to Tanzi (1978), inflation may negatively affect tax revenue. Demand for goods and services will tend to fall when the rate of inflation increases. The real value of money is experiencing a drop during inflation, which undermines people's purchasing power. When the decreased purchasing power, then generally, the number of goods and services demanded will decrease. When the number of goods demanded decreases, the public consumption of goods and services will also decline. It will diminish the basis of the government's tax revenue.

According to Agbeyegbe, Stotsky and WoldeMariam (2004), trade openness has a close relationship with tax revenue, primarily through its effect on international trade taxes. One of the steps used by the government to increase trade openness is by reducing tariffs (Ebrill et al., 1999). Trade liberalization causes a decrease in import duties, thus reducing international trade tax revenues.

Aizenman and Jinjarak (2009) revealed a solid and positive relationship between tax revenue and trade openness. Gupta (2007) also finds that the level of tax revenue to GDP ratio increases when the level of trade openness of a country increases. According to Ebrill, Stotsky and Gropp (1999), the positive relationship between taxation and trade is strongly influenced by the increasing intensity of import and export transactions when liberalization policies are implemented. In addition, the positive effect of trade liberalization on tax revenue also depends on several factors, such as the structure of the tax system and administrative capabilities (Khattry \& Mohan Rao, 2002). Agbeyegbe, Stotsky and WoldeMariam (2004) argued that trade openness could positively affect tax revenue if supported by sound monetary policy. Thus, it can be concluded that economic openness has an ambiguous effect on tax revenue.

\section{RESEARCH METHODOLOGY}

This research uses secondary data collected from World Development Indicators (WDI) provided by the World Bank for seven ASEAN countries (Indonesia, Malaysia, Thailand, Singapore, Philippines, Cambodia, and Laos) between 2009 and 2015. Referring to previous studies, we consider that a country's tax revenue is influenced by several macroeconomic factors: per capita income, the industrial sector's GDP, inflation rate, and trade liberalization. We employ the panel data regression analysis to estimate the extent of the impact of each factor on tax revenue. The regression model that we will use can be expressed as follows:

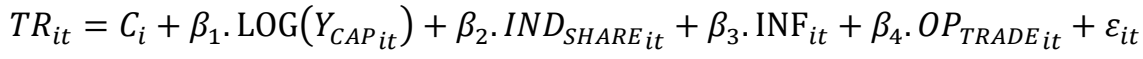

Where,

$T R_{i t}$ represents tax revenue of country $i$ at time $t$ (\% of GDP).

- $\quad \operatorname{LOG}\left(Y_{C A P i t}\right)$ represents GDP per capita of country $i$ at time $t$ (Current US\$ and log-transformed).

- $\quad I N D_{\text {SHARE }_{i t}}$ represents value-added of industrial sector of country $i$ at time $t$ (\% of GDP).

- $\quad \mathrm{INF}_{i t}$ represents inflation rate calculated by the consumer price index of country $i$ at time $t$ (annual \%).

This publication is licensed under Creative Commons Attribution CC BY.

http://dx.doi.org/10.29322/IJSRP.11.08.2021.p11657

WWW.ijsrp.org 
- $O P_{\text {TRADE }}$ it represents total import and export of country $i$ at time $t$ (\% of GDP).

- $\quad C_{i}(i=1 \ldots n)$ represents the unknown intercept for each country ( $n$ country-specific intercepts),

- $\quad \varepsilon_{i t}$ is the error term assumed to be non independently and identically distributed (i.i.d).

- $\quad \beta_{1}, \beta_{2}, \beta_{3}$, and $\beta_{4}$ represent the coefficient for $\operatorname{LOG}\left(Y_{C A P i t}\right), I N D_{S H A R E}$ t, $\operatorname{INF}_{i t}$, and $O P_{T R A D E}{ }_{i t}$, respectively.

The regression model presented by equation [1] is called the fixed-effect (FE) model. The main feature of this model is the subscript $i$ in the intercept term $(C)$, which indicates that the intercepts of the seven countries may be different. This difference may be influenced by the unique character of each country, such as tax compliance, regulations, and tax policy instruments. Taking this situation into account, we can avoid biasness parameters in our panel data regression. In addition, the net effect of each country can be obtained. To allow the intercept value to vary between countries, we can use the Least Squares Dummy Variable (LSDV) technique, as Gujarati (2003) suggested. Therefore, we can write model [2] as follows:

$$
\begin{gathered}
T R_{i t}=C_{1}+C_{2} \cdot D_{2 i}+C_{3} \cdot D_{3 i}+C_{4} \cdot D_{4 i}+C_{5} \cdot D_{5 i}+C_{6} \cdot D_{6 i}+C_{7} \cdot D_{7 i}+\beta_{1} \cdot \operatorname{LOG}\left(Y_{C A P_{i t}}\right)+\beta_{2} \cdot I_{N D_{S H A R E} i t}+\beta_{3} \cdot \operatorname{INF}_{i t} \\
+\beta_{4} \cdot O P_{T R A D E_{i t}}+\varepsilon_{i t}
\end{gathered}
$$

Where,

- $\quad D_{2 i}=1$ if the observations belong to Indonesia, 0 otherwise;

- $\quad D_{3 i}=1$ if the observations belong to Laos, 0 otherwise.

- $\quad D_{4 i}=1$ if the observations belong to Malaysia, 0 otherwise.

- $\quad D_{5 i}=1$ if the observations belong to the Philippines, 0 otherwise.

- $\quad D_{6 i}=1$ if the observations belong to Singapore, 0 otherwise.

- $\quad D_{7 i}=1$ if the observations belong to Thailand, 0 otherwise.

Since we have seven states, we can only use six dummies (D) to avoid the dummy variable trap, namely the situation of perfect collinearity (Gujarati, 2003). Thus, we are not dummy for Cambodia. In other words, $C_{2}, C_{3}, C_{4}, C_{5}$, and $C_{7}$ are intercepts from Indonesia, Laos, Malaysia, Philippines, Singapore, Thailand. In short, Cambodia is a comparison country. It must be noted that there are no standard rules for selecting comparison countries (Gujarati, 2003).

Following the ideas of previous studies as outlined in the previous section of this paper, we expect per capita income to have a positive sign because it captures both the income and "ability to pay" lines of people in a country. The industrial sector variable as a percentage of GDP is also expected to have a positive sign. We argue that companies operating in this sector have excellent and detailed financial reports compared to other sectors. It makes it easier for tax officials to collect taxes from them.

Inflation is expected to harm tax revenue because it tends to distort purchasing power rather than stimulate growth. The decline in people's purchasing power discourages the economy, which in turn reduces tax revenues. Trade openness is thought to have an ambiguous effect on taxation. On the one hand, liberalization shows an increase in economic enthusiasm, which impacts increasing taxes. On the other hand, liberalization indicates cutting international trade tariffs, which means lowering tax revenues. Thus, this paper has the following hypothesis:

- $\quad$ H1: Per capita income positively affects the tax revenue ( $\beta_{1}$ is positive).

- $\quad$ H2: Industrial sectors positively affects the tax revenue $\left(\beta_{2}\right.$ is positive).

- H3: Inflation negatively affects the tax revenue ( $\beta_{2}$ is negative).

- H4: Trade Openness positively or negatively affects the tax revenue ( $\beta_{4}$ is positive or negative).

To accurately prove the hypothesis, we need to ensure that the model [2] is correctly specified. For this reason, we carried out the Hausman test to determine whether the FE model presented in the model [2] can estimate the effect of each independent variable on the outcome of interest $\left(T R_{i t}\right)$ or not. The initial hypothesis of this test gives the answer no, which means that the alternative model, namely the random-effect (RE) model, is more suitable for estimating the regression model [2].

The results of the Hausman test do not provide any evidence regarding the parameters in the model [2] that have met the Best Linear Unbiased Estimator (BLUE) criteria. We have to do a diagnostic test to find out whether the disturbance in the model [2] is free from the problems of heteroscedasticity, autocorrelation, and the very general form of cross-sectional dependence or not. These three problems are often encountered in regression analysis with panel data. To run the autocorrelation test, we used the Woodridge test. The Modified Wald test is carried out for the heteroscedasticity test. The Breusch-Pagan LM test is used to determine the existence of cross-sectional dependence in the model.

\section{RESULTS AND DISCUSSION}

Table 1 provides the main results of this study. According to the Table, the Hausman test results state that the null hypothesis of the inconsistent FE model is rejected with its p-value below 0.01. Thus, we can use the FE model shown by equation [2] to produce consistent parameters. The results of the Wooldridge test show that the null hypothesis of the disturbance is not accepted because the p-value of this test is above the 10\% significance limit. The Modified Wald test results show that the model's error terms contain homoscedastic problems because the p-value is less than 0.01. Finally, the Breusch-Pagan LM test suggests that our residuals across individual countries in our baseline model are correlated at the $10 \%$ significance level. In summary, our FE model has heteroscedasticity and cross-sectional dependence problems, which makes our parameters not meet the BLUE criteria.

Therefore, Driscoll and Kraay's (1998) standard errors need to be used since it is consistent for cross-sectionally dependent and heteroskedastic disturbance. Our FE model equipped with this standard error is shown in column 2 of Table 1. To ensure that the FE 
model is selected correctly, we again run a robust Hausman test. The test results in the same conclusion as the initial one that the FE model is consistent in estimating the tax ratio regression [2].

Table 1. Tax Ratio Regression Results

\begin{tabular}{|c|c|c|c|c|}
\hline \multirow{2}{*}{ Models } & \multicolumn{2}{|c|}{ LSDV } & \multicolumn{2}{|c|}{$\mathrm{RE}$} \\
\hline & (1) & (2) & (3) & (4) \\
\hline LOGYCAPit & $\begin{array}{r}4.906782 * * * \\
(0.6874248)\end{array}$ & $\begin{array}{c}4.906782 * * * \\
(0.653501)\end{array}$ & $\begin{array}{c}2.384043 * * * \\
(0.6753629)\end{array}$ & $\begin{array}{c}2.384043 * * * \\
(0.8685191)\end{array}$ \\
\hline$I N D_{S_{H A R E}}$ it & $\begin{array}{c}0.2283554 * * \\
(0.1094465)\end{array}$ & $\begin{array}{c}0.2283554 * * * \\
(0.0589954)\end{array}$ & $\begin{array}{l}-0.0008139 \\
(0.0975778)\end{array}$ & $\begin{array}{c}-0.0008139 \\
(0.056405)\end{array}$ \\
\hline $\mathrm{INF}_{i t}$ & $\begin{array}{c}-0.1439092 * * \\
(0.0621136)\end{array}$ & $\begin{array}{c}-0.1439092 * * * \\
(0.013351)\end{array}$ & $\begin{array}{l}-0.0446155 \\
(0.0799823)\end{array}$ & $\begin{array}{l}-0.0446155 \\
(0.0845982)\end{array}$ \\
\hline$O P_{T R A D E_{i t}}$ & $\begin{array}{l}0.0249914 * \\
(0.012581)\end{array}$ & $\begin{array}{c}0.0249914 * * \\
(0.0096093) \\
\end{array}$ & $\begin{array}{l}-0.0088912 \\
(0.0097153)\end{array}$ & $\begin{array}{r}-0.0088912 \\
(0.010447) \\
\end{array}$ \\
\hline$D_{2 i}$ & $\begin{array}{c}-5.960767 * * * \\
(1.896104)\end{array}$ & $\begin{array}{c}-5.960767 * * \\
(1.653168)\end{array}$ & & \\
\hline$D_{3 i}$ & $\begin{array}{c}3.602864 * * * \\
(0.8801413)\end{array}$ & $\begin{array}{l}3.602864 * * \\
(1.195543)\end{array}$ & & \\
\hline$D_{4 i}$ & $\begin{array}{c}-10.91253 * * * \\
(2.01364)\end{array}$ & $\begin{array}{c}-10.91253 * * * \\
(1.791459)\end{array}$ & & \\
\hline$D_{5 i}$ & $\begin{array}{c}-3.135915^{* *} \\
(1.457825) \\
\end{array}$ & $\begin{array}{l}-3.135915^{*} \\
(1.390679)\end{array}$ & & \\
\hline$D_{6 i}$ & $\begin{array}{c}-24.68545^{* * *} \\
(3.503785) \\
\end{array}$ & $\begin{array}{c}-24.68545^{* * * *} \\
(2.441966) \\
\end{array}$ & & \\
\hline$D_{7 i}$ & $\begin{array}{c}-7.795605^{* * * *} \\
(2.174972)\end{array}$ & $\begin{array}{c}-7.795605 * * * \\
(1.46242)\end{array}$ & & \\
\hline Constant & $\begin{array}{c}-28.1817 * * * \\
(5.353169)\end{array}$ & $\begin{array}{c}-28.1817 * * * \\
(3.338334)\end{array}$ & $\begin{array}{l}-5.172522 \\
(5.327156)\end{array}$ & $\begin{array}{l}-5.172522 \\
(8.350683)\end{array}$ \\
\hline $\mathrm{R}^{2}$ & 0.9022 & 0.9022 & 0.1170 & 0.1170 \\
\hline Observations & 49 & 49 & 49 & 49 \\
\hline Countries & 7 & 7 & 7 & 7 \\
\hline Hausman test & {$[0.0000]^{* * *}$} & {$[0.0001]^{* * *}$} & & \\
\hline Wooldridge test & [0.3703] & & & \\
\hline Modified Wald test & {$[0.0001]^{* * *}$} & & & \\
\hline Breusch-Pagan LM test & {$[0.0583]^{*}$} & & & \\
\hline
\end{tabular}

Notes: Standard errors are in parentheses. Driscoll-Kraay standard errors are reported in columns 2 and 4 in parentheses. Robust Hausman test is reported in column 2. $P$-values are in square brackets. $*=$ significant at $10 \%$ level. $* *=$ significant at $5 \%$ level. *** $=$ significant at $1 \%$ level.

In addition, we can see that the statistical significance of the estimated coefficients and the value of the coefficient of determination (R2) displayed by column 2 in Table 1 increased substantially. Each of these two facts confirms that the FE model with DriscollKraay Standard errors is better than the FE model in column 1 and the RE model with Driscoll-Kraay standard errors in column 3. The R2 value of the specified FE model (column 2) is equal to 0.9022. It shows that the model's independent ability can explain the variation in the value of the dependent variable by $90 \%$, and other variables outside the model explain the rest. Thus, we can conclude that if the FE model used in this study is applied to the population, the probability of obtaining a similar variation in the value of the tax-to-GDP ratio is $90 \%$. Therefore, we will only focus on the research results presented in column 2 of Table 1. Appendix displays equation [2] rewritten by entering the estimated coefficient value displayed by column 2 of Table 1.

As mentioned earlier, the consequence of using the FE model is that we have to consider the country-specific intercepts. In other words, the value of intercepts of each country is different but does not vary over time; that is, it is time-invariant. The specification of the FE model is visualized with the coefficient value of each dummy variable shown in column (2). Adding dummies into the regression model is very appropriate when the FE model is specified. It will yield the net effect of the regression on the outcome of interest $\left(T R_{i t}\right)$. In addition, our regression model will also avoid the issue of omitted variable bias (see Appendix $\mathrm{B}$ for a formal explanation).

Since this study uses seven countries, the intercept values incorporated into the model are only for six countries. It must be done to avoid the dummy variable trap in the model. Therefore, there are no dummy variables for the country of Cambodia. In other words, - 
28.1817 is the intercept value of Cambodia in the model. By doing so, the intercept values of each country are; Indonesia is -34.1425 $(=-28.1817-5.960767)$, Laos is $-24.5788(=-28.1817+3.602864)$, Malaysia is $-39.0942(=-28.1817-10.9125)$, the Philippines is $-31.3176(=-28.1817-3.13592)$, Singapore is $-52,8672(=-28.1817-24.6855)$, and Thailand is $-35.9773(=-28.1817-7.79561)$. The average of all intercepts in that fixed effects model is -35.1656 . The big difference in the intercept value may be due to special features of each country, such as tax compliance, regulation, taxation policy instruments, and others. The highest intercept value of all countries is Cambodia, which amounted to $-28,182$. In comparison, the lowest intercept value in Singapore, which amounted to 52,867 .

The intercept value of each country is the value of the tax ratio when all the independent variables are equal to zero. Negative numbers from the intercept value in each country illustrate that without the independent variables, such countries require other revenue sources. The most probable source of revenue is non-tax revenue. It is because the non-tax revenue has the second-largest contribution after-tax in all seven countries in ASEAN. Alternatively, if we take the possibility of worse, the government in all seven countries must undertake foreign or domestic debt to finance the government's activities. By looking at these possibilities, the negative figure of the intercepts indicates the importance of economic factors as other regressors to optimize tax revenue in all seven countries.

Based on column 2 in Table 1, the value of slope coefficient of per capita income is 4.907. It indicates that increasing per capita income by $1 \%$ will increase the tax-to-GDP ratio by about 4,907 percentage points, ceteris paribus. In addition, the $p$-value of this variable is significant even at the $1 \%$ significance level. Hence, it can be concluded that the per capita income has a positive and significant effect on tax revenue. The Estimated coefficient of per capita income is the largest compared to other variables. It proves that per capita income is very superior in influencing tax revenue compared to other macroeconomic factors. It may be due to the increase in per capita income directly represents an improvement in the level of economic development, demand for public goods and services, and the "ability to pay", which in turn encourages the flow of government tax revenues significantly. This result is consistent with research on the factors that affect tax revenue in various countries, such as the research conducted by Gaalya (2015), Agbeyegbe, Stotsky and WoldeMariam (2004), Ahmad et al. (2016), and Gupta (2007).

The sector's contribution to GDP was also found to affect the ratio of tax revenue to GDP positively. On average, a one-percentagepoint increase in industrial value-added as a percentage of GDP will increase by about one-fifth of a percentage point in actual tax revenue, all other things being equal. The estimated coefficient size of this variable is the second largest after per capita income. In addition, the significant effect of industrial variable parameters is greater than that of the FE model in column 1 . It can reject the null hypothesis even at the $1 \%$ significance level.

The findings indicate that the shift in economic structure towards industrialization will significantly increase governments' revenues from taxation. According to the business field, some countries such as Indonesia, Malaysia, Thailand, Singapore, and the Philippines put the industry in a significant GDP sector. In contrast, other countries such as Cambodia and Laos have agricultural sectors that dominate the economy's structure in those countries. However, the agricultural sectors in Cambodia and Laos tend to decrease during the sample period. On the other hand, the industrial sectors tend to increase. It shows that both countries are heading towards industrialization. Indeed the government in the country can take advantage of the industrial sectors as a source of their revenue through taxation.

Unsurprisingly, inflation, as expected, has the opposite effect of the previous two variables on taxation. The negative effect of inflation on tax revenue is shown by the negative value of the slope coefficient of this variable with a size of 0.144 . In this way, a one percentage point increase in the annual inflation rate is associated with a 0.144 percentage point decrease in tax revenue as a share of GDP, assuming all else unchanged. The adverse effect of this variable is incredibly significant on account that the probability value of t-statistics is less than 0.01 . Therefore, it can be said that inflation significantly affects tax revenue.

The results of this study are in line with research conducted by Ghura (1998) and Muibi and Sinbo (2013). The decline in consumer purchasing power when inflation rises is one of the factors causing the decline in tax revenues. It may also be due to the character of most Southeast Asian people who are very responsive to price changes. So the consequence is that an increase in prices will lead to a reduction in the demand for goods and services. As a result, tax revenues, especially those obtained based on goods and services transactions, decreased.

The trade openness variable is also observed to have a positive and significant effect on tax revenue. The effect of the variable is the least significant compared to other variables, namely with a p-value below the 5\% significance level. On average, this suggests that a one percentage point increase in trade liberalization would only lead to a 0.0249914 rise in tax-to-GDP ratio. These results are in line with research conducted by Gaalya (2015), Agbeyegbe, Stotsky and WoldeMariam (2004), and Gupta (2007).

This result is quite reasonable considering that trade openness does not directly affect tax revenue but through its effect on other variables, such as international trade taxes. In addition, not all countries in the sample collect international trade taxes. Singapore is one of the countries that adhere to trade liberalization. So that international trade taxes do not apply domestically. So, although the intensity of international trade is very high, it does not increase tax revenue significantly. As for other countries, although international taxes are set, international trade is not as intensive as Singapore. All of these reasons may cause trade openness to be less significant on tax revenues.

\section{CONCLUSION}

This study investigates the extent to which macroeconomic factors can affect the flow of government tax revenues. To achieve this goal, we use secondary data that is fully obtained from the World Bank. The scope of our research is the Southeast Asian countries

This publication is licensed under Creative Commons Attribution CC BY.

http://dx.doi.org/10.29322/IJSRP.11.08.2021.p11657

WWW.ijsrp.org 
that are members of ASEAN. Due to data availability issues from these countries, we only selected seven countries between 20059 2015.

Thus, panel data regression analysis was used in this study to estimate the impact of each macroeconomic factor on taxes. Referring to the literature, we choose four variables as proxies for macroeconomic factors: income per capita, the industrial sector's contribution to GDP, inflation, and economic openness.

In general, the study reveals that all analyzed variables play a significant role in determining the ratio of tax revenues. Using the FE model, this study finds that a one percent increase in per capita income will increase tax revenue by 4.9 percentage points on average. A one percentage point increase in industrial sector value-added per GDP results in a 0.2 percentage point increase in tax revenue. One percentage point increase in the inflation rate will lower the tax ratio by about 0.1 . One percentage point increase in trading volume will increase tax collection by 0.03 percentage points. The estimation results are consistent with the existence of heteroscedasticity and cross-sectional dependence problems in the model due to Driscoll-Kraay standard errors.

The results of this study lead to several policy implications related to increasing the productivity of tax revenues by considering four macroeconomic factors. Tax revenue bases need to be strengthened by increasing a country's national income. The most common way that can be taken is to use fiscal stimulus instruments and monetary easing. These facilities need to be prioritized to increase productivity and added value of the industrial sector, considering their critical role in influencing tax revenue without prejudice to other sectors, such as agriculture and services. In addition, there is a need for support from the government in the form of policies that encourage international trade activities, especially exports, such as easing tariffs and quotas and improving customs procedures. The government also needs to control inflation so that all previous policies to economic growth are not corrected too profoundly. In this way, people's purchasing power and "ability to pay" in a country can be maintained and increased, thus increasing tax revenues.

APPENDIX A. EQUATION [2] WITH ESTIMATED COEFFICIENTS IN COLUMN 2 OF TABLE 1

$$
\begin{aligned}
& \widehat{T R_{l t}}=-28.1817-\text { 5.961. } D_{2 i}+\text { 3.603. } D_{3 i}-10.913 . D_{4 i}-3.136 . D_{5 i}-24.686 . D_{6 i}-7.796 . D_{7 i}+4.907 . \operatorname{LOG}\left(Y_{C A P}\right) \\
& +0.228 . I N_{\text {SHARE }} i t-0.144 . \mathrm{INF}_{i t}+0.025 . O P_{T R A D E} i t \\
& s e=(3.338) \quad(1.653) \\
& t=(-8.44) \quad(-3.61) \\
& R^{2}=0.902
\end{aligned}
$$

Where $\widehat{T R_{l t}}$ is the predicted value of actual tax revenue as a share of GDP. se is the Driscoll-Kraay standard errors. $t$ is the t-statistics.

\section{APPENDIX B. OMITTED VARIABLE BIAS OF THIS STUDY CONTEXT}

We have equation [2] as our expected model.

$T R_{i t}=C_{1}+C_{2} \cdot D_{2 i}+C_{3} \cdot D_{3 i}+C_{4} \cdot D_{4 i}+C_{5} \cdot D_{5 i}+C_{6} \cdot D_{6 i}+C_{7} \cdot D_{7 i}+\beta_{1} \cdot \operatorname{LOG}\left(Y_{C A P_{i t}}\right)+\beta_{2} \cdot I_{N D_{S H A E}}+\beta_{3} \cdot \mathrm{INF}_{i t}+$ $\beta_{4} . O P_{\text {TRADE }}+\varepsilon_{i t} \quad i=1, \ldots, n ; t=1, \ldots, n$

The Gaus-Markov assumption (G-M assumption) that must be met to obtain the Best Linear Unbiased Estimator (BLUE) parameter is as follows:

$$
\begin{array}{ll}
E\left(\varepsilon_{i t}\right)=0 & i=1, \ldots, n ; t=1, \ldots, n \\
\operatorname{var}\left(\varepsilon_{i t}\right)=\sigma^{2} & i=1, \ldots, n ; t=1, \ldots, n \\
\operatorname{cov}\left(\varepsilon_{i t}, \varepsilon_{j d}\right)=0 & i \neq j ; t \neq d
\end{array}
$$

$D_{2 i}, D_{3 i}, D_{3 i}, D_{4 i}, D_{5 i}, D_{6 i}, D_{7 i}, \operatorname{LOG}\left(Y_{C A P}\right), I N D_{S H A R E}, I_{i t} F_{i t}$, and $O P_{T R A D E}$ it are fixed across $n$.

If we omit the $D_{2 i}, D_{3 i}, D_{3 i}, D_{4 i}, D_{5 i}, D_{6 i}, D_{7 i}$ from the model, then the equation will change to:

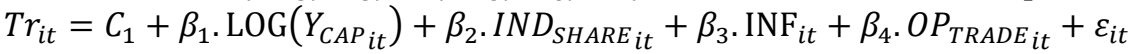

As we know that $\beta_{1}, \beta_{2}, \beta_{3}$, and $\beta_{4}$ are not biased if and only if $\mathrm{E}\left(\beta_{1}, \beta_{2}, \beta_{3}\right.$, and $\left.\beta_{4}\right)=\mathrm{E}\left(\sum \omega_{i t} T R_{i t}\right)=\beta_{1}, \beta_{2}, \beta_{3}$, and $\beta_{4}$. Where $\sum \omega_{i t} T R_{i t}$ is for the linear estimator. To find out whether $\beta_{1}, \beta_{2}, \beta_{3}$, and $\beta_{4}$ meets these requirements, we can apply the algebra of expectations. Thus, obtained: 


$$
\begin{aligned}
\mathrm{E}\left(\beta_{1}, \beta_{2}, \beta_{3}, \text { and } \beta_{4}\right) & =\mathrm{E}\left(\sum \omega_{i t} T R_{i t}\right)=\sum \mathrm{E}\left(\omega_{i t} T R_{i t}\right) \\
& =\sum \omega_{i t} \mathrm{E}\left(T R_{i t}\right) \\
& =\sum \omega_{i t} \mathrm{E}\left(C_{1}+C_{2} \cdot D_{2 i}+C_{3} \cdot D_{3 i}+C_{4} \cdot D_{4 i}+C_{5} . D_{5 i}+C_{6} \cdot D_{6 i}+C_{7} \cdot D_{7 i}+\beta_{1} \cdot \operatorname{LOG}\left(Y_{C A P}\right)+\beta_{2} . I N D_{S H A R E}+\beta_{3} . \mathrm{INF}_{i t}\right. \\
& \left.+\beta_{4} \cdot O P_{T R A D E}+\varepsilon_{i t}\right)=C_{1} \sum \omega_{i t}+C_{2} \sum \omega_{i t} D_{2 i}+C_{3} \sum \omega_{i t} D_{3 i}+C_{4} \sum \omega_{i t} D_{4 i}+C_{5} \sum \omega_{i t} D_{5 i}+C_{6} \sum \omega_{i t} D_{6 i} \\
& +C_{7} \sum \omega_{i t} D_{7 i}+\beta_{1} \sum \omega_{i t} \operatorname{LOG}\left(Y_{C A P i t}\right)+\beta_{2} \sum \omega_{i t} I N D_{S H A R E}+\beta_{3} \sum \omega_{i t} \mathrm{INF}_{i t}+\beta_{4} \sum \omega_{i t} O P_{T R A D E}+\mathrm{E}\left(\varepsilon_{i t}\right),\left(\mathrm{E}\left(\varepsilon_{i t}\right)\right. \\
& =0 \text { according to first } G-M \text { assumpion })
\end{aligned}
$$

OLS knows to impose the constraints for $\sum \omega_{i t} \operatorname{LOG}\left(Y_{C A P_{i t}}\right)=\sum \omega_{i t} I N D_{S H A R E_{i t}}=\sum \omega_{i t} \mathrm{INF}_{i t}=\sum \omega_{i t} O P_{T R A D E_{i t}}=1$ and $\sum \omega_{i t}=0$ but impose no constraints on $\sum \omega_{i t} D_{2 i}=\sum \omega_{i t} D_{3 i}=\sum \omega_{i t} D_{4 i}=C_{5} \sum \omega_{i t} D_{5 i}=\sum \omega_{i t} D_{6 i}=\sum \omega_{i t} D_{7 i}=1$ because $D_{2 i}, D_{3 i}, D_{3 i}, D_{4 i}$, $D_{5 i}, D_{6 i}, D_{7 i}$ are omitted from the model. Thus, the result of the algebra of $\mathrm{E}\left(\beta_{1}, \beta_{2}, \beta_{3}\right.$, and $\left.\beta_{4}\right)$ is as follows:

$\mathrm{E}\left(\beta_{1}, \beta_{2}, \beta_{3}\right.$, and $\left.\beta_{4}\right)=\beta_{1}, \beta_{2}, \beta_{3}$, and $\beta_{4}+C_{2} \sum \omega_{i t} D_{2 i}+C_{3} \sum \omega_{i t} D_{3 i}+C_{4} \sum \omega_{i t} D_{4 i}+C_{5} \sum \omega_{i t} D_{5 i}+C_{6} \sum \omega_{i t} D_{6 i}+C_{7} \sum \omega_{i t} D_{7 i}$

Based on the results of the algebra, it is stated that our estimated coefficient of $\operatorname{LOG}\left(Y_{C A P}\right), I N D_{S H A R E}$, INF It $_{i t}$, and $O P_{T R A D E}$ are consists of two parts: (1) the "true" coefficient of $\operatorname{LOG}\left(Y_{C A P_{i t}}\right), I N D_{S H A R E_{i t}}, \mathrm{INF}_{i t}$, and $O P_{T R A D E}$, which are $\beta_{1}, \beta_{2}, \beta_{3}$, and $\beta_{4}$, respectively; and (2) a term that depends on $D_{2 i}, \quad D_{3 i}, \quad D_{3 i}, \quad D_{4 i}, \quad D_{5 i}, D_{6 i}$, and $D_{7 i}$, which are $C_{2}, C_{3} \sum \omega_{i t} D_{3 i}, C_{4} \sum \omega_{i t} D_{4 i}, C_{5} \sum \omega_{i t} D_{5 i}, C_{6} \sum \omega_{i t} D_{6 i}$, and $C_{7} \sum \omega_{i t} D_{7 i}, \quad$ respectively. Hence, our primary estimators $\left(\beta_{1}, \beta_{2}, \beta_{3}\right.$, and $\left.\beta_{4}\right)$ are biased estimators to predict the fitted value of the outcome of interest $\left(T R_{i t}\right)$.

\section{REFERENCES}

Agbeyegbe, T. D., Stotsky, J. G., \& WoldeMariam, A. (2004). Trade Liberalization, Exchange Rate Changes, and Tax Revenue in Sub-Saharan Africa. IMF Working Papers, WP/04/178. https://doi.org/10.5089/9781451858983.001

Ahmad, H. K., Ahmed, S., Mushtaq, M., \& Nadeem, M. (2016). Socio Economic Determinants of Tax Revenue in Pakistan : An Empirical Analysis. Journal of Applied Environmental and Biological Sciences, 6(2S), 32-42.

Aizenman, J., \& Jinjarak, Y. (2009). Globalisation and developing countries -a shrinking tax base? Journal of Development Studies, 45(5), 653-671. https://doi.org/10.1080/00220380802582338

Ayenew, W. (2016). Determinants of Tax Revenue in Ethiopia (Johansen Co-Integration Approach). International Journal of Business, Economics and Management, 3(6), 69-84. https://doi.org/10.18488/journal.62/2016.3.6/62.6.69.84

Driscoll, J. C., \& Kraay, A. C. (1998). Consistent covariance matrix estimation with spatially dependent panel data. Review of Economics and Statistics, 80(4), 549559. https://doi.org/10.1162/003465398557825

Ebrill, L., Stotsky, J., \& Gropp, R. (1999). Revenue Implications of Trade Liberalization. International Monetary Fund. https://www.elibrary.imf.org/view/books/084/05984-9781557758132-en/05984-9781557758132-en-book.xml

Eltony, M. N. (2002). The Determinants of Tax Effort in Arab Countries. http://www.arab-api.org/images/publication/pdfs/256/256_wps0207.pdf

Fenochietto, R., \& Pessino, C. (2013). Understanding Countries' Tax Effort. IMF Working Paper, WP/13/244. https://doi.org/10.5089/9781484301272.001

Gaalya, M. S. (2015). Trade Liberalization and Tax Revenue Performance in Uganda. Modern Economy, 06(02), 228-244. https://doi.org/10.4236/me.2015.62021

Ghura, D. (1998). Tax Revenue in Sub-Saharan Africa: Effects of Economic Policies and Corruption. IMF Working Papers, WP/98/135. https://doi.org/10.5089/9781451855685.001

Gujarati, D. N. (2003). Basic Econometrics. In The Economic Journal (Vol. 82, Issue 326). McGraw Hill Book Co. https://doi.org/10.2307/2230043

Gupta, A. Sen. (2007). Determinants of Tax Revenue Efforts in Developing Countries. IMF Working Paper, WP/07/184. https://www.imf.org/en/Publications/WP/Issues/2016/12/31/Determinants-of-Tax-Revenue-Efforts-in-Developing-Countries-21040

III, R. J. E. (2005). Provision and Production of Public Goods (1st ed.). In Handbook of Public Sector Economics (pp. 209-232). Routledge. https://doi.org/10.4324/9781315093185

Immervoll, H. (2005). Falling up the Stairs: The Effects of "Bracket Creep" on Household Incomes. Review of Income and Wealth, 51(1), 37-62. https://doi.org/10.1111/j.1475-4991.2005.00144.x

Karagöz, K. (2013). Determinants of Tax Revenue: Does Sectorial Composition Matter? Journal of Finance, Accounting and Management, 4(2), 50-63. https://www.proquest.com/openview/dc694d2a4aec528cd4f3a559f1812268/1.pdf?pq-origsite=gscholar\&cbl=2032035\&casa_token=RFysiOL6PEAAAAA:FVPMmtKLcWz9ZMHE9sMIB1wc_ShULSbejU8E9-bsIZ7eciF9UuYheanwjMUWezk052GER5sxzqIt

Khattry, B., \& Mohan Rao, J. (2002). Fiscal faux pas?: An Analysis of the Revenue Implications of Trade Liberalization. World Development, 30(8), 1431-1444. https://doi.org/10.1016/S0305-750X(02)00043-8

Muibi, S. O., \& Sinbo, O. O. (2013). Macroeconomic Determinants of Tax Revenue in Nigeria ( 1970-2011 ). World Applied Sciences Journal, $28(1), 27-35$. https://doi.org/10.5829/idosi.wasj.2013.28.01.1189

Musgrave, R. A. (1939). The Voluntary Exchange Theory of Public Economy. Quarterly Journal of Economics, 53(2), 213-237. https://doi.org/10.2307/1882886

Prammer, D., \& Reiss, L. (2015). Impact of Inflation on Fiscal Aggregates in Austria. Monetary Policy \& The Economy, Q1(15), 27-41. https://www.oenb.at/dam/jcr:9744bd80-5752-4c05-bd97-8229511210fb/mop_2015_q1_analyses3.pdf

Stiglitz, J. E. (1991). The Invisible Hand and Modern Welfare Economics. NBER Working Paper, 3641. https://doi.org/10.3386/w3641

Tanzi, V. (1978). Inflation, Real Tax Revenue, and the Case for Inflationary Finance - Theory With an Application To Argentina. International Monetary Fund Staff Papers, 25(3), 417-451. https://doi.org/10.5089/9781451972559.024 


\section{ACKNOWLEDGMENT}

We are grateful to Siti Khodijah for her helpful comments and suggestions for this work. We also gratefully acknowledge financial support from Pratama Kreston Tax Research Institute. Everything written in this paper is solely our views as the authors and does not represent our institutions. Therefore, any mistakes and errors in this paper are entirely the responsibility of the authors.

\section{AUTHORS}

First Author - Prianto Budi Saptono, Lecturer, Faculty of Administrative Sciences, Universitas Indonesia, prianto.saptono@ui.ac.id Second Author - Gustofan Mahmud, Researcher, Pratama Kreston Tax Research Institute, gustofan@ pratama.co.id

Correspondence Author - Prianto Budi Saptono, prianto.saptono@ui.ac.id, +62-811-906-181 